\title{
Prognostic and metastasis-related factors in colorectal neuroendocrine tumors: A cross-sectional study based on the Surveillance, Epidemiology and End Results
}

\author{
JINMAO ZOU ${ }^{1,2^{*}}$, SHANGXIANG CHEN ${ }^{1,2^{*}}$, GUODA LIAN $^{1,2}$, RUOMENG LI $^{1,2}$, \\ YAQING $\mathrm{LI}^{1,2}$, KAIHONG HUANG ${ }^{1,2}$ and YINTING CHEN ${ }^{1,2}$ \\ ${ }^{1}$ Guangdong Provincial Key Laboratory of Malignant Tumor Epigenetics and Gene Regulation; \\ ${ }^{2}$ Department of Gastroenterology, Sun Yat-Sen Memorial Hospital, Sun Yat-Sen University, \\ Guangzhou, Guangdong 510120, P.R. China
}

Received January 14, 2019; Accepted August 1, 2019

DOI: $10.3892 / \mathrm{ol} .2019 .10876$

\begin{abstract}
The incidence of colorectal neuroendocrine tumors (NETs) is gradually increasing with the increasing availability of colonoscopy and computed tomography. However, prognostic and metastatic factors for colorectal NETs are unknown. The aim of the present study was to identify clinicopathological prognostic and metastasis-related risk factors for colorectal NETs. Based on the Surveillance, Epidemiology and End Results (SEER) program, the data of 3,093 patients with colorectal NETs were included in the present study. $\chi^{2}$ test, crosstabulation, Kaplan-Meier method, Cox proportional hazard regression model, nomogram and logistic regression analysis were used to evaluate the risk factors. Systemic analysis of data from 3,093 patients revealed that age $(\mathrm{P}<0.001)$, marital status $(\mathrm{P}<0.001)$, number of malignant tumors $(\mathrm{P}<0.001)$, histopathological grade $(\mathrm{P}<0.001)$ and clinical stage $(\mathrm{P}<0.001)$ were independent prognostic factors of cancer-specific survival (CSS). Among them, married patients exhibited longer CSS compared with unmarried patients $(\mathrm{P}<0.05)$. A nomogram based on these five factors
\end{abstract}

Correspondence to: Professor Kaihong Huang or Professor Yinting Chen, Department of Gastroenterology, Sun Yat-Sen Memorial Hospital, Sun Yat-Sen University, 107 Yanjiang West Road, Guangzhou, Guangdong 510120, P.R. China

E-mail: huangkh@mail.sysu.edu.cn

E-mail: chenyt58@mail.sysu.edu.cn

${ }^{*}$ Contributed equally

Abbreviations: NETs, neuroendocrine tumors; CSS, cancer-specific survival; SEER, Surveillance, Epidemiology and End Results; CgA, chromogranin A; HR, hazard ratio; 95\% CI, 95\% confidence interval; AJCC, American Joint Committee on Cancer; ROC, receiver operating characteristic; AUC, area under the curve

Key words: neuroendocrine tumors, colorectal, prognosis, metastasis, Surveillance, Epidemiology and End Results with an area under the curve of 0.921 [95\% confidence interval (CI), 0.908-0.934; $\mathrm{P}<0.001]$ was constructed. Age $(\mathrm{P}=0.010)$, primary tumor site $(\mathrm{P}<0.001)$, surgery $(\mathrm{P}<0.001)$, tumor size $(\mathrm{P}<0.001)$ and histopathological grade $(\mathrm{P}<0.001)$ were risk factors for distant metastasis of colorectal NETs. In conclusion, age, marital status, number of malignant tumors, histopathological grade and clinical stage may be independent prognostic factors for CSS of colorectal NETs, and the nomogram may have higher predictive efficiency compared with clinical stage. Age, primary tumor site, surgery, tumor size and histopathological grade may be risk factors for the distant metastasis of colorectal NETs.

\section{Introduction}

The incidence of neuroendocrine tumors (NETs) in the United States increased 6.4 times between $1973(1.09 / 100,000)$ and 2012 (6.98/100,000), however the overall 5-year survival rate of NETs has also increased, the overall survival rate for all NETs improved between 2000 and 2004 to 2009 and 2012 [hazard ratio (HR), 0.79; 95\% confidence interval (CI), 0.73-0.85] (1). Currently, the majority of studies on prognostic factors of digestive system NETs focus on those with primary locations in the pancreas, stomach and small intestine. Ter-Minassian et al (2) reported that when distant metastases occur in NETs, cancer-specific survival (CSS) time is shorter in male patients with advanced age, primary pancreatic tumors and higher histopathological grade. For patients with advanced pancreatic, small bowel and other NETs, chromogranin A ( $\mathrm{CgA})$ is a highly useful prognostic indicator (3). In non-functioning pancreatic NETs, lymph node metastasis is an independent factor of overall survival, and a tumor size $<2 \mathrm{~cm}$ is a protective factor for lymph node metastasis (4). Although the prognostic and predictive factors for metastasis of NETs have been examined, the research methods and findings of these studies vary, resulting in considerable heterogeneity among the studies (5-8). To the best of our knowledge, a limited number of studies have focused on the prognostic and metastatic factors of colorectal NETs. They have become the most common NETs in the digestive tract, as 
the incidence of colorectal NETs has exceeded that of NETs in the pancreas, small intestine and other parts of the digestive system (1). The reason for the increased incidence of digestive tract NETs may be due to the widespread clinical application of high-resolution computed tomography and colonoscopy (9). However, prognostic and metastatic risk factors for colorectal NETs remain unclear.

In the present study, the Surveillance, Epidemiology, and End Results (SEER) database was used to study data from patients with colorectal NETs and to identify the possible risk factors of NETs. Based on the examined risk factors, a novel nomogram was proposed to predict the CSS of colorectal NETs.

\section{Materials and methods}

Project design and medical record selection. All medical records were obtained from the SEER database (https://seer. cancer.gov), which provides information on cancer statistics with the aim of reducing the cancer burden among the US population (10). SEER is supported by the Surveillance Research Program of the National Cancer Institute's Division of Cancer Control and Population Sciences. The SEER*Stat software (version 8.3.5; https://seer.cancer.gov/seerstat/) was used to obtain detailed clinicopathological information from patients with colorectal NETs. The criteria for the selection of medical records were: i) The data was collected between 1973-2004, as some covariates were introduced in the SEER database in 2004; ii) tumor site was limited to colon and rectum; and iii) the histopathological type code was used according to the NET International Classification of Diseases codes for 'carcinoid tumors' (8240/3), 'enterochromaffin cell carcinoid' (8241/3), 'composite carcinoid' (8244/3), 'adenocarcinoid' (8245/3), 'neuroendocrine carcinoma' (8246/3), 'atypical carcinoid tumor' (8249/3), 'stromal carcinoid' (9091/3), 'islet cell carcinoma' (8150/3) and 'mixed islet cell/exocrine adenocarcinoma' (8154/3) (11). The records with the age of diagnosis $<18$ years, unclear status of the 7th edition of the American Joint Committee on Cancer (AJCC) staging (12) and incomplete information of CSS status were excluded.

Variable selection. According to the rules of collection of SEER data, the variables involved in the present study were classified based on the type of data collected by SEER . Marital status was divided into married and unmarried. The latter was divided into four categories: i) Single (never married); ii) divorced; iii) separated; and iv) widowed. The age grouping interception was automatically calculated by SPSS version 22.0 (IBM Corporation), which provided the best discrimination of cancer-specific survival. Race/ethnicity was defined as Caucasian and other.

As the prognosis of patients with colorectal NETs was distinctive from other colorectal tumors, the survival rate of cecum, ascending colon, transverse colon, descending colon, sigmoid colon and rectal NETs were previously assessed (Fig. S1). It was indicated that patients with rectal NETs had the best survival rate, closely followed by sigmoid colon. Survival analysis showed no statistically significant difference between NETs at sigmoid colon and rectum. NETs at the ascending, transverse and descending colon had the worst survival, however results were also not statistically significant. Combining with the conventional classification of gastrointestinal tumors, which categorizes tumors based on the anatomical location of the disease, such as the tumor originating in the stomach was classified into gastric cancer, colorectal NETs in the present study were classified into three categories: i) Cecum; ii) ascending/transverse/descending colon; and iii) sigmoid colon/rectum. Surgery was divided into two subgroups of 'Yes' or 'No'. Tumor size was divided into two groups of $>4$ and $\leq 4 \mathrm{~cm}$. Histopathological grade was recorded as undifferentiated/poorly differentiated, moderately differentiated and well differentiated in the SEER database and using the 7th AJCC staging system these were defined as low, intermediate and high histopathological grades, respectively before analysis (10). In the SEER database, the specific cause of death is an indicator of the CSS of a certain disease (10). In the present study, colorectal NETs were used as the specific cause of death.

Statistical analysis. All data was presented as mean \pm standard deviation. Statistical analysis was performed using SPSS version 22.0 (IBM Corporation). The baseline demographic and clinicopathological information were analyzed using the Descriptive Statistics function in SPSS. Spearman's correlation analysis was used to initially explore the potential correlation between the demographic and clinicopathological factors, such as the correlation between 7th AJCC stage (12) and primary tumor site. Kaplan-Meier method and log-rank (Mantel-Cox) analysis were used to visualize and compare the survival curves of each factor on CSS, respectively. Receiver operating characteristic curve (ROC) analysis was performed to reveal the risk prediction ability of each potential factor for NETs distant metastasis, and to compare the predictive power of the nomogram and clinical staging system to the CSS of NETs. Univariate analysis was used to initially explore a number of variables associated with CSS. Multivariate analysis was used to screen variables with independent prognostic effects and construct Cox proportional hazard regression models. Crosstabulation and $\chi^{2}$ tests were used to analyze the distribution of marital status in the age group and surgery group. The nomogram was generated by R software (version 3.5.1; The R Foundation for Statistical Computing). Binary logistic regression analysis was used to obtain variables associated with distant metastases. All P-values were two-sided. $\mathrm{P}<0.05$ was considered to indicate a statistically significant difference.

\section{Results}

Patient characteristics. Of the 3,093 patients, $48.9 \%$ were male and $51.1 \%$ were female. The clinicopathological characteristics of patients are presented in Table I. The median age was $57.86 \pm 12.30$ years. SPSS software automatically divided the intercept points, and the age was divided into two groups: $<70$ and $\geq 70$ years. A total of $\sim 97.45 \%$ of the patients had insurance, and there was a significant difference in the distribution of insurance and no insurance $(\mathrm{P}<0.001)$. Of all patients, $62.75 \%$ were married. The majority of the patients $(92.79 \%)$ had undergone surgical treatment. The primary tumor site was most commonly in the sigmoid colon/rectum (71.71\%). The total number of malignant tumors did not exceed 2 in the majority of patients $(96.50 \%)$, and $67.63 \%$ of the patients 
Table I. Baseline demographic and clinical characteristics of 3,093 patients with colorectal neuroendocrine tumors in Surveillance, Epidemiology and End Results databases.

\begin{tabular}{|c|c|}
\hline Characteristics & $\begin{array}{c}\text { Total, } \\
\mathrm{n}=3,093\end{array}$ \\
\hline \multicolumn{2}{|l|}{ Age, years } \\
\hline$<70$ & 2,579 \\
\hline$\geq 70$ & 514 \\
\hline \multicolumn{2}{|l|}{ Sex } \\
\hline Male & 1,512 \\
\hline Female & 1,581 \\
\hline \multicolumn{2}{|l|}{ Race } \\
\hline Caucasian & 1,964 \\
\hline Other & 1,129 \\
\hline \multicolumn{2}{|l|}{ Insurance } \\
\hline Yes & 3,014 \\
\hline No & 79 \\
\hline \multicolumn{2}{|l|}{ Marital status } \\
\hline Married & 1,941 \\
\hline Unmarried $^{\mathrm{a}}$ & 1,152 \\
\hline \multicolumn{2}{|l|}{ Tumor site } \\
\hline Sigmoid colon/Rectum & 2,218 \\
\hline Cecum & 544 \\
\hline Asc/Transv/Desc colon & 331 \\
\hline \multicolumn{2}{|l|}{ Surgery } \\
\hline Yes & 2,870 \\
\hline No & 223 \\
\hline \multicolumn{2}{|l|}{ Tumor size, $\mathrm{cm}$} \\
\hline$\leq 4$ & 2,273 \\
\hline$>4$ & 820 \\
\hline \multicolumn{2}{|c|}{ Malignant tumors (,$\leq 2$ vs. $>2$ ) } \\
\hline$\leq 2$ & 2,985 \\
\hline$>2$ & 108 \\
\hline \multicolumn{2}{|l|}{ Histopathological grade ${ }^{b}$} \\
\hline High & 2,092 \\
\hline Intermediate & 842 \\
\hline Low & 159 \\
\hline \multicolumn{2}{|c|}{ 7th American Joint Committee on cancer stage ${ }^{c}$} \\
\hline I & 1,870 \\
\hline II & 239 \\
\hline III & 552 \\
\hline IV & 432 \\
\hline
\end{tabular}

${ }^{a}$ Unmarried includes single, divorced, separated and widowed. Asc/Transv/Desc, ascending/transverse/descending. ' ${ }^{\text {Histopatho- }}$ logical grade was transformed from undifferentiated/poorly differentiated to low, moderately differentiated to intermediate, and well differentiated to igh (10). ${ }^{c}(12)$.

had histopathological high-grade tumors. According to the 7 th edition of the AJCC staging system, $60.46 \%$ of the 3,093 patients were stage I, $7.73 \%$ were stage II, $17.85 \%$ were
Table II. Correlation analysis between independent variables and the probable confounding variables analyzed by Spearman's rho.

\begin{tabular}{lll}
\hline Interaction factors & $\begin{array}{c}\text { Correlation } \\
\text { coefficient }\end{array}$ & P-value \\
\hline 7 th American Joint $^{\text {Committee on cancer stage }}$ & & \\
Primary tumor site & $0.693^{\mathrm{b}}$ & $<0.001$ \\
Tumor size & $0.443^{\mathrm{b}}$ & $<0.001$ \\
$\quad$ Surgery & $0.177^{\mathrm{b}}$ & $<0.001$ \\
Histopathological grade & & \\
Primary tumor site & $0.409^{\mathrm{b}}$ & $<0.001$ \\
Tumor size & $0.252^{\mathrm{b}}$ & $<0.001$ \\
Surgery & $0.184^{\mathrm{b}}$ & $<0.001$ \\
\hline
\end{tabular}

${ }^{\mathrm{a}}(12)$. ${ }^{\mathrm{b}}$ Correlation is significant at the 0.001 level (2-tailed). ${ }^{\mathrm{c}} \mathrm{His}-$ topathological grade was transformed from undifferentiated/poorly differentiated to low, moderately differentiated to intermediate, and well differentiated to high (10).

stage III and $13.96 \%$ were stage IV. Correlation analysis was performed to identify the factors that were likely to be relevant among these clinicopathological factors; as a result, both clinical stage and histopathological grade showed significant correlation with primary tumor site, tumor size and surgery (Table II).

Prognostic and metastasis risk factor screening and nomogram. Kaplan-Meier survival analysis was used to identify the association between prognostic factors and CSS of patients with colorectal NETs (Fig. 1). In the age groups of $<70$ and $\geq 70$ years, the CSS significantly decreased with increasing age $(\mathrm{P}<0.001)$. For marital status, CSS rate of the unmarried group was significantly lower compared with that of the married group $(\mathrm{P}<0.001)$. The effect of marital status on CSS of colorectal NETs was further studied; crosstabulation and $\chi^{2}$ test were used to analyze the distribution of marital status in the age (Table SI) and surgery groups (Table SII). A higher proportion of married patients in the age $<70$ group, and a lower proportion in the age $\geq 70$ group compared with unmarried patients were observed $(\mathrm{P}<0.001$; Table $\mathrm{SI})$. In the surgery groups, compared with unmarried patients, the proportion of married patients who underwent surgical treatment was higher, and the proportion of patients who did not receive surgical treatment was lower $(\mathrm{P}=0.001$; Table $\mathrm{SII})$. The survival function between the primary tumor site and CSS suggested that the CSS of patients with colorectal NETs in the sigmoid colon/rectum was higher compared with that of patients with NETs in the cecum or ascending/transverse/descending colon $(\mathrm{P}<0.001)$. CSS reduced as the total number of malignant tumors increased $(\mathrm{P}<0.001)$. Fig. 1 also demonstrates that the prognosis of patients that underwent surgery was improved compared with that of patients who did not undergo surgery HR, 1.275; CI, 1.126-1.444; $\mathrm{P}<0.001$. Patients with NETs with low histopathological grade had shorter survival time compared with those with high grade. The 7 th edition of the AJCC staging system successfully distinguished the survival conditions of the 3,093 patients. The ROC curve (Fig. 2) was 

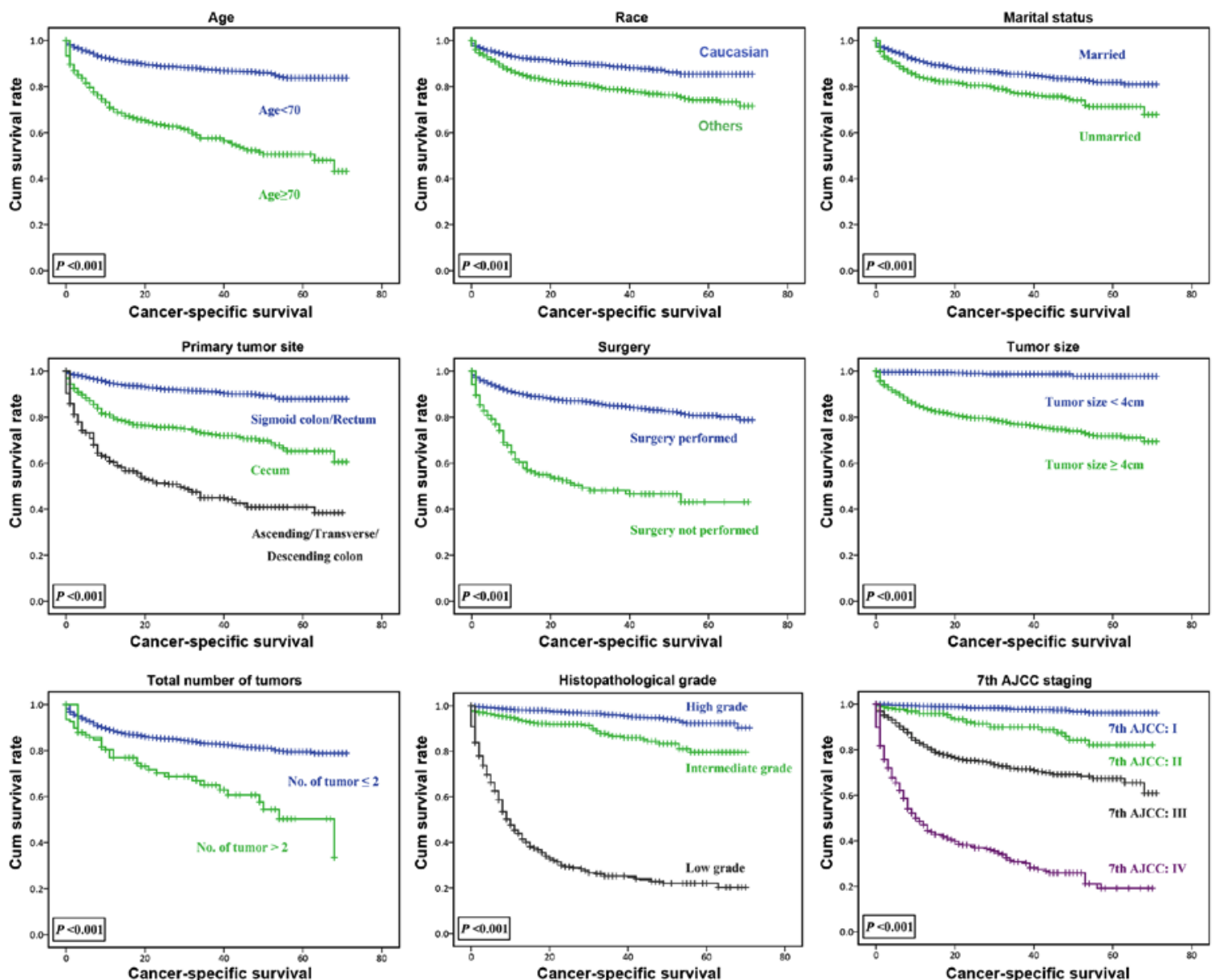

Figure 1. Survival function reflecting the association between age, race, marital status, primary tumor site, surgery, tumor size, total number of tumors, histopathological grade, clinical staging and cancer-specific survival. The 7th AJCC staging system was used for the assessment of the size of the primary tumor, local invasion, lymph node metastasis, and distant metastasis. Histopathological grade is a grading system utilized to assess the differentiation of tumors. Cumulative survival rate refers to the cumulative probability of the survival rate after a period of time. Cum survival, cumulative survival; AJCC, American Joint Committee for Cancer.
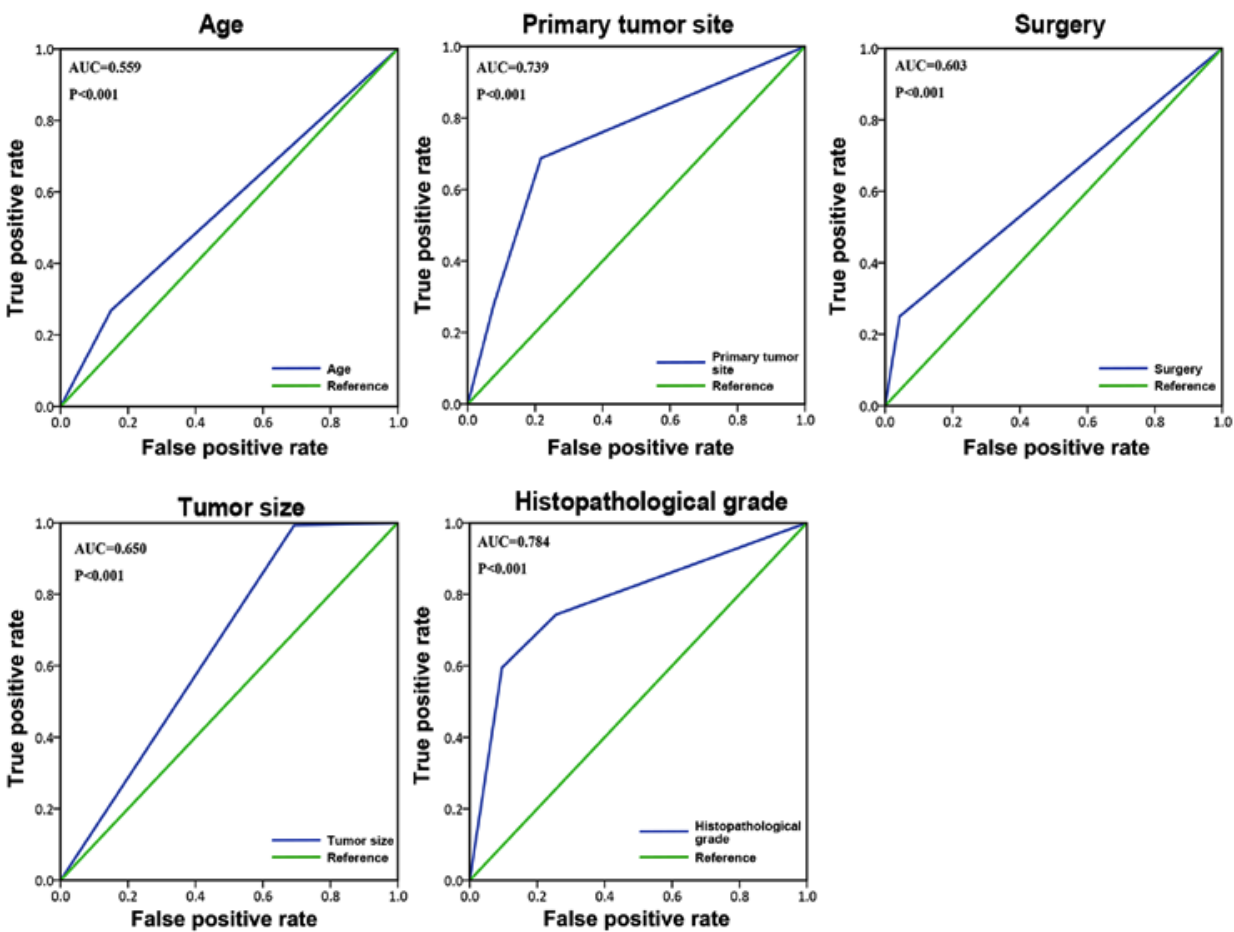

Figure 2. Receiver operating characteristic curves illustrate the accuracy of age, primary tumor site, surgery, tumor size, histopathological grade in predicting the distant metastasis of colorectal NETs. Histopathological grade is a grading system utilized to assess the differentiation of tumors. 
Table III. Univariate analysis with hazard ratios of baseline characteristics for cancer-specific survival in patients with colorectal neuroendocrine tumors.

\begin{tabular}{|c|c|c|}
\hline Variable & Hazard ratio (95\% confidence interval) & P-value ${ }^{a}$ \\
\hline Age (<70 vs. $\geq 70$ years $)$ & $4.113(3.407-4.966)$ & $<0.001$ \\
\hline Sex (female vs. male) & $1.152(0.957-1.387)$ & 0.134 \\
\hline Race (Caucasian vs. other) & $1.976(1.585-2.464)$ & $<0.001$ \\
\hline Insurance (yes vs. No) & $1.306(0.767-2.225)$ & 0.325 \\
\hline Marital status (married vs. unmarried ${ }^{b}$ ) & $1.682(1.397-2.024)$ & $<0.001$ \\
\hline Tumor site & & $<0.001$ \\
\hline Sigmoid colon/rectum & Ref. & \\
\hline Cecum & $3.590(2.847-4.525)$ & $<0.001$ \\
\hline Asc/Transv/Desc colon & $8.477(6.795-10.575)$ & $<0.001$ \\
\hline Surgery (yes vs. no) & $4.369(3.474-5.494)$ & $<0.001$ \\
\hline Tumor size $(\leq 4 \mathrm{~cm}$ vs. $>4 \mathrm{~cm})$ & $20.631(10.253-41.513)$ & $<0.001$ \\
\hline Malignant tumors (n, $\leq 2$ vs. $>2$ ) & $2.471(1.765-3.459)$ & $<0.001$ \\
\hline Histopathological grade ${ }^{c}$ & & $<0.001$ \\
\hline High & Ref. & \\
\hline Intermediate & $3.150(2.191-4.529)$ & $<0.001$ \\
\hline Low & $31.652(24.388-41.078)$ & $<0.001$ \\
\hline 7th American Joint Committee on cancer stage ${ }^{d}$ & & $<0.001$ \\
\hline I & Ref. & \\
\hline II & $5.304(3.081-9.132)$ & $<0.001$ \\
\hline III & $15.255(10.259-22.684)$ & $<0.001$ \\
\hline IV & $58.410(39.994-85.308)$ & $<0.001$ \\
\hline
\end{tabular}

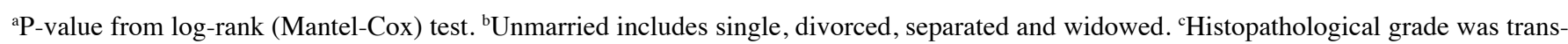
formed from undifferentiated/poorly differentiated to low, moderately differentiated to intermediate, and well differentiated to high (10). ${ }^{\mathrm{d}}(12)$. Ref, indicates the subgroup that was used as a referential group. Asc/Transv/Desc, ascending/transverse/descending.

used to demonstrate the value of the aforementioned five metastasis-related variables: Age, primary tumor site, surgery, tumor size, and histopathological grade. Among all the risk factors for metastasis, histopathological grade [area under the curve (AUC), 0.784; $\mathrm{P}<0.001]$ and age (AUC, 0.559; $\mathrm{P}<0.001$ ) exhibited the maximum and minimum AUC. Univariate analysis was used to initially examine a number of variables associated with CSS (Table III). Based on the results of the univariate analysis, variables with $\mathrm{P}<0.05$ were used as statistically significant variables. Combining the results of the univariate and correlation analyses, relevant variables were incorporated into the Cox proportional hazard regression model to obtain an unadjusted model (Table IV). A total of five independent prognostic factors were identified, including age, marital status, number of malignant tumors, histopathological grade and clinical stage. HRs and 95\% CIs for each independent prognostic variable and two other adjusted Cox proportional hazards regression models are presented in Table IV. After adjustment by demographic and clinical pathological factors, the histopathological grade (low) and 7th AJCC staging system in the adjusted model 2 all showed a decrease in HR value and decreased by $>10 \%$ compared with the unadjusted model.

Based on these Cox proportional hazards regression models, a nomogram containing five factors was constructed (Fig. 3A).
The calibration curve (Fig. 3B) revealed moderate accuracy of the nomogram, and the ROC curve (Fig. 3C) indicated that the nomogram (AUC, 0.921; $\mathrm{P}<0.001$ ) had higher predictive power compared with the 7 th edition of AJCC staging system (AUC, 0.850; $\mathrm{P}<0.001$ ).

Nomogram scoring system. According to the nomogram calculation, when age is $<70$ years, the score is 0 , whereas when age is $\geq 70$ years, the score is 25 points (Fig. 3A). Married patients are assigned 0 points, whereas unmarried patients are assigned 24 points. AJCC stages I, II, III, IV are assigned corresponding scores of $0,6,50$ and 100, respectively. Total number of tumors $\leq 2$ is assigned 0 points, whereas $>2$ tumors gain a score of 24 . The scores of low, intermediate and high histopathological grades are 84, 19 and 0, respectively.

For example, patient 1 aged 67 years, unmarried (divorced), with AJCC stage III, had a total number of tumors $>2$ (three tumors), and the histopathological grade was intermediate (moderately differentiated). The 1-, 3- and 5-year CSS predicted by the nomogram was 90,70 and $60 \%$, respectively.

Risk factors for distant metastasis were analyzed using logistic regression analysis. A total of five distant metastasis relative risk factors were identified, including age, primary tumor site, surgery, tumor size and histopathological grade. This model was adjusted for demographics of race, sex, 
Table IV. Multivariate analysis with hazard ratios for cancer-specific survival in patients with colorectal neuroendocrine tumors.

\begin{tabular}{|c|c|c|c|c|c|c|}
\hline \multirow[b]{2}{*}{ Variables } & \multicolumn{2}{|l|}{ Unadjusted model } & \multicolumn{2}{|c|}{ Adjusted model $1^{\mathrm{a}}$} & \multicolumn{2}{|c|}{ Adjusted model $2^{\mathrm{b}}$} \\
\hline & $\mathrm{HR}(95 \% \mathrm{CI})$ & P-value & $\mathrm{HR}(95 \% \mathrm{CI})$ & P-value & HR $(95 \%$ CI) & P-value \\
\hline \multicolumn{7}{|l|}{ Age, years } \\
\hline$<70$ & Ref. & & Ref. & & Ref & \\
\hline$\geq 70$ & $1.667(1.365-2.035)$ & $<0.001$ & $1.758(1.436-2.151)$ & $<0.001$ & $1.693(1.378-2.080)$ & $<0.001$ \\
\hline \multicolumn{7}{|l|}{ Marital status } \\
\hline Married & Ref. & & Ref. & & Ref. & \\
\hline Unmarried $^{c}$ & $1.736(1.438-2.096)$ & $<0.001$ & $1.806(1.488-2.190)$ & $<0.001$ & $1.811(1.492-2.199)$ & $<0.001$ \\
\hline \multicolumn{7}{|l|}{ Malignant tumors, $\mathrm{n}$} \\
\hline$\leq 2$ & Ref. & & Ref. & & Ref. & \\
\hline$>2$ & $2.177(1.542-3.075)$ & $<0.001$ & $2.326(1.641-3.297)$ & $<0.001$ & $2.273(1.601-3.227)$ & $<0.001$ \\
\hline Histopathological grade ${ }^{\mathrm{d}}$ & & $<0.001$ & & $<0.001$ & & $<0.001$ \\
\hline High & Ref. & & Ref. & & Ref. & \\
\hline Intermediate & $1.923(1.329-2.783)$ & 0.001 & $1.957(1.352-2.832)$ & 0.001 & $1.909(1.319-2.763)$ & 0.001 \\
\hline Low & 9.977 (7.404-13.444) & $<0.001$ & $10.254(7.596-13.842)$ & $<0.001$ & $8.771(6.258-12.293)$ & $<0.001$ \\
\hline 7th American Joint & & $<0.001$ & & $<0.001$ & & $<0.001$ \\
\hline \multicolumn{7}{|l|}{$\begin{array}{l}\text { Committee on Cancer } \\
\text { stage }^{\mathrm{e}}\end{array}$} \\
\hline I & Ref. & & Ref. & & Ref. & \\
\hline II & $1.542(0.870-2.732)$ & 0.138 & $1.447(0.814-2.574)$ & 0.208 & $1.094(0.596-2.008)$ & 0.771 \\
\hline III & $4.525(2.939-6.966)$ & $<0.001$ & $4.566(2.958-7.048)$ & $<0.001$ & $3.266(2.008-5.313)$ & $<0.001$ \\
\hline IV & $16.343(10.746-24.856)$ & $<0.001$ & $16.501(10.845-25.105)$ & $<0.001$ & $11.490(7.118-18.548)$ & $<0.001$ \\
\hline
\end{tabular}

insurance status, marital status and clinical characteristics of the total number of malignant tumors (Table V).

\section{Discussion}

Based on the 3,093 medical records from the SEER database, age, marital status, number of malignant tumors, histopathological grade and clinical stage were identified to be independent prognostic factors for colorectal NETs. Therefore, a novel nomogram to predict the survival of colorectal NETs was proposed; the calibration and AUC curve indicated that the nomogram had a higher predictive power compared with the AJCC staging system. In addition, age, primary tumor site, surgery, primary tumor size and histopathological grade were risk factors associated with distant metastasis of colorectal NETs.

Multivariate analysis revealed that age, marital status, number of malignant tumors, histopathological grade and clinical stage were stable and independent variables of CSS. Unadjusted model, adjusted model 1 and adjusted model 2 were compared, which revealed that after adjusting for demographic variables and demographic plus clinicopathological variables, the HRs of the five variables mentioned above were roughly stable. Of note, following adjustment, the HR of clinical stage and histopathological grade (low) decreased by $>10 \%$ compared with unadjusted model. The results of the correlation analysis between demographic and clinicopathological variables demonstrated that the variables used to adjust the model were significantly correlated with the clinical stage and histopathological grade, which may explain why the HRs of these two factors decreased following adjustment. In addition, patients with AJCC stage II exhibited no statistically significant differences in CSS compared with patients in stage I, which suggested that the prognostic discrimination of stage I and stage II in the 7 th edition of the AJCC staging system may need to be improved. These results were consistent with a previous study (13).

The association between marital status and disease is currently an intriguing topic, as a number of researchers have reported a protective effect of marriage on various malignancies, such as bladder cancer and non-small cell lung cancer (14-16). As marital status affects a wide range of diseases, it was hypothesized that an association would exist between marital status and colorectal NETs. In the present study, married patients with NETs had longer CSS compared 

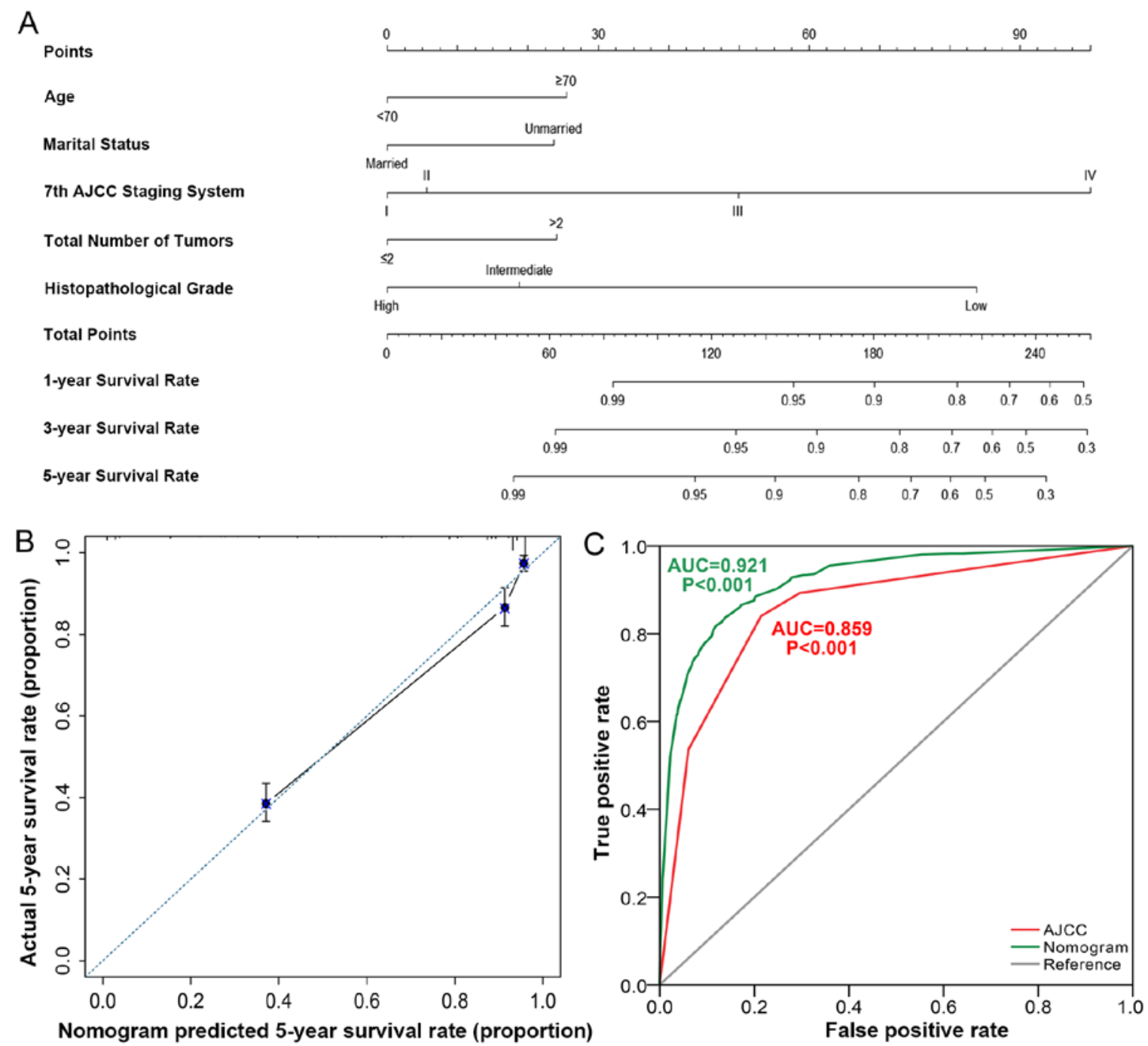

Figure 3. Nomogram predicts the cancer-specific survival rate of patients with neuroendocrine tumors. (A) Nomogram was constructed based on five factors: Age, marital status, AJCC stage, total number of tumors and histopathological grade. (B) Calibration curve of the nomogram demonstrated the predictive power of nomogram. Error bars indicate the margin of error for predicting the 5-year survival rate. (C) Receiver operating characteristic curve comparison between the nomogram and the 7th AJCC staging system. The 7th AJCC staging system was used for the assessment of the size of the primary tumor, local invasion, lymph node metastasis, and distant metastasis. AJCC, American Joint Committee for Cancer; AUC, area under the curve.

with unmarried patients. Although the association between marital status and disease has been suggested by a number of studies, to the best of our knowledge the possible protective effect of marital status in colorectal NETs was proposed for the first time in the present study. The role of marriage, especially social support and its consistent and substantial impact on colorectal NET treatment, intervention and survival was further examined. These results indicate that investments in social-targeted support for vulnerable populations, for example, unmarried patients, may increase the possibility of treatment and improve the survival of patients with colorectal NETs.

Marriage serves a protective role in a number of diseases, including prostate and bladder cancer $(14,15,17)$. A number of studies have suggested that the protective effect of marriage is likely associated with better access to care in married patients compared with unmarried patients (18-20). The encouragement from spouse and increased medication adherence are the likely factors associated with the protective role of marital status $(21,22)$. In addition, married patients have a more stable emotional state and are less prone to anxiety or depression (23). Previous studies have demonstrated that married patients exhibit lower levels of cortisol and more stable circadian rhythms; factors beneficial for CSS and overall survival rate (24-28).

A number of studies have suggested that that cohabitation may bias the analysis of CSS based on the four marital statuses registered in SEER $(16,29,30)$. In the present study, the marital status had a statistically significant protective effect on CSS. As only married vs. unmarried patients were compared, the effect of cohabitation in a limited number of patients cannot be omitted, but the protective effect of marriage existed in the present study.

No statistically significant association was observed between marital status and distant metastasis of colorectal NETs in the present study. However, Aizer et al (31) reported that married patients with any one of ten cancers (lung, colorectal, breast, pancreatic, prostate, liver/intrahepatic 
Table V. Logistic regression analysis of associated factors in colorectal neuroendocrine tumor metastasis.

\begin{tabular}{|c|c|c|c|c|}
\hline Variable & $\mathrm{OR}^{\mathrm{a}}(95 \% \mathrm{CI})$ & P-value & $\mathrm{OR}^{\mathrm{b}}(95 \% \mathrm{CI})$ & P-value \\
\hline \multicolumn{5}{|l|}{ Age, years } \\
\hline$<70$ & Ref. & & Ref. & \\
\hline$\geq 70$ & $0.670(0.493-0.909)$ & 0.010 & $0.686(0.503-0.937)$ & 0.018 \\
\hline Tumor site & & & & $<0.001$ \\
\hline Sigmoid colon/rectum & Ref. & & Ref. & \\
\hline Cecum & $6.246(4.534-8.605)$ & $<0.001$ & $6.510(4.683-9.049)$ & $<0.001$ \\
\hline Asc/transv/desc colon & $3.486(2.390-5.085)$ & $<0.001$ & $3.555(2.425-5.211)$ & $<0.001$ \\
\hline \multicolumn{5}{|l|}{ Surgery } \\
\hline Yes & Ref. & & Ref. & \\
\hline No & $8.531(5.686-12.799)$ & $<0.001$ & $8.374(5.564-12.601)$ & $<0.001$ \\
\hline \multicolumn{5}{|l|}{ Tumor size, cm } \\
\hline$\leq 4$ & Ref. & & Ref. & \\
\hline$>4$ & $15.925(5.004-50.683)$ & $<0.001$ & $16.340(5.130-52.048)$ & $<0.001$ \\
\hline Histopathological grade ${ }^{c}$ & & & & $<0.001$ \\
\hline High & Ref. & & Ref. & \\
\hline Intermediate & $1.752(1.227-2.501)$ & 0.002 & $1.761(1.232-2.517)$ & 0.002 \\
\hline Low & $5.007(3.530-7.102)$ & $<0.001$ & $5.042(3.545-7.172)$ & $<0.001$ \\
\hline
\end{tabular}

${ }^{\mathrm{a} O R}$ Odds ratio of unadjusted logistic binary regression model; ${ }^{\mathrm{b}} \mathrm{OR}$ Odds ratio adjusted for demographics of race, sex, insurance status, marital status, clinical characteristics of total number of malignant tumors. ${ }^{c}$ Histopathological grade was transformed from undifferentiated/poorly differentiated to low, moderately differentiated to intermediate, and well differentiated to high (10). Ref, indicates the subgroup that was used as a referential group. Asc/Transv/Desc, ascending/transverse/descending; OR, odds ratio; CI, confidence interval.

bile duct, head/neck, ovarian and esophageal cancers and non-Hodgkin's lymphoma) had a lower risk of distant metastases compared with unmarried patients. As the present study was conducted using data from only $\sim 3,000$ patients, a larger cohort study may help explain this phenomenon.

Insurance has been associated with protective effects in a number of cancer-associated studies, for example, breast and lung cancer $(32,33)$. However, in the present study, results suggested that there was no statistically significant difference between insurance status and overall survival of colorectal NETs. The heterogeneity of data may account for this, as only 79 patients $(2.55 \%)$ were uninsured. In addition, the detailed information of insurance classification was not recorded in SEER data. Therefore, the corresponding hierarchical analysis of the types of insurance was lacking in the current study. A larger and more targeted designed cohort study is required to uncover the association between insurance and the prognosis of colorectal NETs.

Based on the five factors, age, marital status, 7th AJCC staging system, total number of tumors, and histopathological grade, a novel nomogram of colorectal NETs with a high AUC was proposed in the present study, which demonstrated increased discrimination ability compared with the 7th AJCC staging system. The nomogram integrated not only clinical stage, but also other factors that may affect the CSS of patients with NETs, such as age, total tumor number, histopathological grade and marital status. The associations between age, total tumor number, histopathological grade and CSS were linear; the older the age, the greater the number of primary tumors and the lower the histopathological grade of the tumor, the worse the overall survival of the patients. This is common in cancers, such as breast cancer, leukemia and lymphoma (34-36).

The possible limitations of this study should be considered. First, data related to other clinical histopathological indicators, such as $\mathrm{CgA}$ and $\mathrm{Ki}-67$, are not available in SEER database. However, the level of plasma $\mathrm{CgA}$ is usually normal in poorly differentiated G3 NETs (37). Second, with the exception of the basic records associated with surgery, the medical records in the SEER database do not include other information on patients, such as various health care conditions or socioeconomic factors and the use of cigarettes and alcohol, which may be associated with CSS.

Despite these limitations, the present study has identified independent prognostic factors associated with CSS of patients with colorectal NETs: Age, marital status, number of malignant tumors, histopathological grade and clinical stage. The protective effects of marital status in the CSS of colorectal NETs were analyzed. Based on these five factors, a novel nomogram was constructed to predict CSS. In addition, the risk factors associated with distant metastasis of colorectal NETs were identified: Age, primary tumor site, surgery, tumor size and histopathological grade. Caregivers and medical professionals concerned about patients with colorectal NETs should be aware of the relative factors associated with the prognosis of this population, and may use the nomogram to predict CSS to inform the assessment of prognosis and the choice of coping strategies for the disease. 


\section{Acknowledgements}

Not applicable.

\section{Funding}

This work was supported by the National Natural Science Foundation of China (grant nos. 81572396 and 81672408), the Natural Science Foundation of Guangdong Province, China (grant nos. 2014A030313050 and 2018A030310227), the Specialized Research Fund for the Doctoral Program of Higher Education (grant no. 20130171120093), the Program of Science and Technology Star of Zhujiang Guangzhou City, China (grant no. 201610010078), the Science and Technology Program of Guangzhou, China (grant no. 201508020013), the Science and Technology Planning Project of Guangdong Province, China (grant no. 2013B021800233), the Key Laboratory of Malignant Tumor Molecular Mechanism and Translational Medicine of Guangzhou Bureau of Science and Information Technology (grant no. 2013163), the Key Laboratory of Malignant Tumor Gene Regulation and Target Therapy of Guangdong Higher Education Institutes (grant no. KLB09001), the Medical Scientific Research Foundation of Guangdong Province, China (grant no. A2016210), the Fundamental Research Funds for the Central University (grant no. 18zxxt59) and the Medical Scientific Research Foundation of Guangdong Province, China (grant no. A2018012).

\section{Availability of data and materials}

The datasets generated and/or analyzed during the current study are available in the SEER database, https://seer.cancer.gov.

\section{Authors' contributions}

$\mathrm{KH}$ and $\mathrm{YC}$ conceived and designed the study, and revised the manuscript. JZ, SC and GL prepared the manuscript and completed statistical analysis. RL and YL acquired and processed the data. All authors read and approved the final manuscript.

\section{Ethics approval and consent to participate}

Not applicable.

\section{Patient consent for publication}

Not applicable.

\section{Competing interest}

The authors declare that they have no competing interests.

\section{References}

1. Dasari A, Shen C, Halperin D, Zhao B, Zhou S, Xu Y, Shih T and Yao JC: Trends in the incidence, prevalence, and survival outcomes in patients with neuroendocrine tumors in the united states. JAMA Oncol 3: 1335-1342, 2017.

2. Ter-Minassian M, Chan JA, Frauenhoffer CS, Hooshmand SM, Asomaning K, Lin X, Christiani DC and Kulke MH: Prospective analysis of clinical outcomes and prognostic factors in patients with neuroendocrine tumors (NETs). J Clin Oncol 28: 4044-4044, 2010.
3. Ter-Minassian M, Chan JA, Hooshmand SM, Brais LK, Daskalova A, Heafield R, Buchanan L, Qian ZR, Fuchs CS, Lin $\mathrm{X}$, et al: Clinical presentation, recurrence, and survival in patients with neuroendocrine tumors: Results from a prospective institutional database. Endocr Relat Cancer 20: 187-196, 2013.

4. Toste PA, Kadera BE, Tatishchev SF, Dawson DW, Clerkin BM, Muthusamy R, Watson R, Tomlinson JS, Hines OJ, Reber HA and Donahue TR: Nonfunctional pancreatic neuroendocrine tumors $<2 \mathrm{~cm}$ on preoperative imaging are associated with a low incidence of nodal metastasis and an excellent overall survival. J Gastrointest Surg 17: 2105-2113, 2013.

5. Scherubl H: Tumor biology and prognosis of gastrointestinal carcinoids. J Clin Oncol 26: 6012-6013, 2008.

6. Yao JC, Hassan M, Phan A, Dagohoy C, Leary C, Mares JE, Abdalla EK, Fleming JB, Vauthey JN, Rashid A and Evans DB: One hundred years after 'carcinoid': Epidemiology of and prognostic factors for neuroendocrine tumors in 35,825 cases in the United States. J Clin Oncol 26: 3063-3072, 2008.

7. Franko J, Feng W, Yip L, Genovese E and Moser AJ: Non-functional neuroendocrine carcinoma of the pancreas: Incidence, tumor biology, and outcomes in 2,158 patients. J Gastrointest Surg 14: 541-548, 2010.

8. Wilson C: Cancer: Neuroendocrine tumours-prognostic insights Nat Rev Endocrinol 9: 133, 2013.

9. Lawrence B, Gustafsson BI, Chan A, Svejda B, Kidd M and Modlin IM: The epidemiology of gastroenteropancreatic neuroendocrine tumors. Endocrinol Metab Clin North Am 40: 1-18, 2011.

10. National Cancer Institute: The Surveillance, Epidemiology, and End Results (SEER) Program. Cancer Statistics, SEER Data \& Software, Registry Operations. https://seer.cancer.gov. Accessed May 30, 2018.

11. Fraenkel M, Kim MK, Faggiano A and Valk GD: Epidemiology of gastroenteropancreatic neuroendocrine tumours. Best Pract Res Clin Gastroenterol 26: 691-703, 2012.

12. American Joint Committee on Cancer: AJCC 7th Ed Cancer Staging Manual. https://cancerstaging.org/references-tools/deskreferences/Pages/default.aspx. Accessed May 30, 2018.

13. Gao S, Pu N, Liu L, Li C, Xu X, Wang X and Lou W: The latest exploration of staging and prognostic classification for pancreatic neuroendocrine tumors: A large population-based study. J Cancer 9: 1698-1706, 2018.

14. Nelles JL, Joseph SA and Konety BR: The impact of marriage on bladder cancer mortality. Urol Oncol 27: 263-267, 2009.

15. Neuman MD and Werner RM: Marital status and postoperative functional recovery. JAMA Surg 151: 194-196, 2016.

16. Jatoi A, Novotny P, Cassivi S, Clark MM, Midthun D, Patten CA, Sloan J and Yang P: Does marital status impact survival and quality of life in patients with non-small cell lung cancer? Observations from the mayo clinic lung cancer cohort. Oncologist 12: 1456-1463, 2007.

17. Nepple KG, Kibel AS, Sandhu GS, Kallogjeri D, Strope SA and Grubb RL: Impact of marital status on prostate cancer-specific mortality and overall mortality after radical prostatectomy. J Clin Oncol 30: 73-73, 2012.

18. Vallgarda S: Addressing individual behaviours and living conditions: Four Nordic public health policies. Scand J Public Health 39 (Suppl): 6-10, 2011.

19. Arntzen A and Nybo Andersen AM: Social determinants for infant mortality in the Nordic countries, 1980-2001. Scand J Public Health 32: 381-389, 2004.

20. Jakobsen L, Niemann T, Thorsgaard N, Thuesen L, Lassen JF, Jensen LO, Thayssen P, Ravkilde J, Tilsted HH, Mehnert F and Johnsen SP: Dimensions of socioeconomic status and clinical outcome after primary percutaneous coronary intervention. Circ Cardiovasc Interv 5: 641-648, 2012.

21. Aizer AA, Paly JJ, Zietman AL, Nguyen PL, Beard CJ, Rao SK, Kaplan ID, Niemierko A, Hirsch MS, Wu CL, et al: Multidisciplinary care and pursuit of active surveillance in low-risk prostate cancer. J Clin Oncol 30: 3071-3076, 2012.

22. Cohen SD, Sharma T, Acquaviva K, Peterson RA, Patel SS and Kimmel PL: Social support and chronic kidney disease: An update. Adv Chronic Kidney Dis 14: 335-344, 2007.

23. Uecker JE: Marriage and mental health among young adults. J Health Soc Behav 53: 67-83, 2012.

24. Goldzweig G, Andritsch E, Hubert A, Brenner B, Walach N, Perry S and Baider L: Psychological distress among male patients and male spouses: What do oncologists need to know? Ann Oncol 21: 877-883, 2010. 
25. Sephton SE, Sapolsky RM, Kraemer HC and Spiegel D: Diurnal cortisol rhythm as a predictor of breast cancer survival. J Natl Cancer Inst 92: 994-1000, 2000.

26. Weissman MM, Bland RC, Canino GJ, Faravelli C, Greenwald S, Hwu HG, Joyce PR, Karam EG, Lee CK, Lellouch J, et al: Cross-national epidemiology of major depression and bipolar disorder. JAMA 276: 293-299, 1996.

27. Sephton SE, Lush E, Dedert EA, Floyd AR, Rebholz WN, Dhabhar FS, Spiegel D and Salmon P: Diurnal cortisol rhythm as a predictor of lung cancer survival. Brain Behav Immun 30 (Suppl): S163-S170, 2013

28. DiMatteo MR, Lepper HS and Croghan TW: Depression is a risk factor for noncompliance with medical treatment: Meta-analysis of the effects of anxiety and depression on patient adherence. Arch Intern Med 160: 2101-2107, 2000.

29. Schaefer EW, Wilson MZ, Goldenberg D, Mackley H, Koch W and Hollenbeak CS: Effect of marriage on outcomes for elderly patients with head and neck cancer. Head Neck 37: 735-742, 2015.

30. Lowery WJ, Stany MP, Phippen NT, Bunch KP, Oliver KE, Tian C, Maxwell GL, Darcy KM and Hamilton CA: Survival advantage of marriage in uterine cancer patients contrasts poor outcome for widows: A surveillance, epidemiology and end results study. Gynecol Oncol 136: 328-335, 2015.

31. Aizer AA, Chen MH, McCarthy EP, Mendu ML, Koo S, Wilhite TJ, Graham PL, Choueiri TK, Hoffman KE, Martin NE, et al: Marital status and survival in patients with cancer. J Clin Oncol 31: 3869-3876, 2013.
32. Ellis L, Canchola AJ, Spiegel D, Ladabaum U, Haile R and Gomez SL: Trends in cancer survival by health insurance status in california from 1997 to 2014. JAMA Oncol 4: 317-323, 2018.

33. Halpern MT, Ward EM, Pavluck AL, Schrag NM, Bian J and Chen AY: Association of insurance status and ethnicity with cancer stage at diagnosis for 12 cancer sites: A retrospective analysis. Lancet Oncol 9: 222-231, 2008.

34. Shapiro CL: Cancer Survivorship. N Engl J Med 379: 2438-2450, 2018.

35. Xie S and Hossain MJ: Survival differences in childhood and young adult acute myeloid leukemia: A cross-national study using us and england data. Cancer Epidemiol 54: 19-24, 2018.

36. Villano JL, Koshy M, Shaikh H, Dolecek TA and McCarthy BJ: Age, gender, and racial differences in incidence and survival in primary CNS lymphoma. Br J Cancer 105: 1414-1418, 2011.

37. Oberg K, Knigge U, Kwekkeboom D, Perren A and ESMO Guidelines Working Group: Neuroendocrine gastro-entero-pancreatic tumors: ESMO clinical practice guidelines for diagnosis, treatment and follow-up. Ann Oncol 23 (Suppl): vii124-vii130, 2012.

This work is licensed under a Creative Commons Attribution-NonCommercial-NoDerivatives 4.0 International (CC BY-NC-ND 4.0) License. 